\title{
O POSITIVISMO NA TEORIA DESCRITIVISTA DE BLOOMFIELD
}

\section{POSITIVISM IN BLOOMFIELD'S DESCRIPTIVIST THEORY}

\author{
Roberlei Alves Bertucci ${ }^{1}$ \\ Recebido para publicação em 10/11/2007 \\ Aceito para publicação em 01/03/2008
}

\begin{abstract}
"A revolução positiva consiste essencialmente em substituir sempre a inacessível determinação das causas propriamente ditas, pela simples investigação das leis.”

Auguste Comte
\end{abstract}

\section{RESUMO}

Este artigo se propõe a apresentar algumas características gerais presentes na concepção de ciência e na metodologia utilizada pelo estruturalismo bloomfieldiano - também conhecido como descritivismo - que podem ser encontradas de forma integral ou similar na filosofia positivista de Auguste Comte. Entre essas características, pode-se destacar o rigor na observação e descrição dos fatos - sociais e lingüísticos - e a busca por um resultado preciso da descrição, capaz de prever a ocorrência dos mesmos fatos em outras situações -- sociais ou lingüísticas.

Palavras-chave: descritivismo; estruturalismo americano; Bloomfield; positivismo.

\begin{abstract}
This paper wants to present some general characteristics of the methodology and science conception in the Bloomfieldian structuralism - knew as descriptivism too - that are founded totally or partially in the August Comte's positivist philosophy. Among theses characteristics, we can highlight the strict observation and description of the facts - social and linguistics - and the search for a accurate result of the description, able to predict the occurrence of the same facts in others situations -social or linguistics.
\end{abstract}

Key words: descriptivism; American structuralism; Bloomfield; positivism.

\footnotetext{
${ }^{1}$ Graduado em Letras Português Inglês pela Pontifícia Universidade Católica do Paraná, mestre em Letras (Estudos Lingüísticos) pela Universidade Federal do Paraná e doutorando em Lingüística pela USP. roberlei.bertucci@pop.com.br
} 


\section{Introdução}

O fazer científico é sempre uma questão intrigante. Quando se diz, por exemplo, que a lingüística é uma ciência, tem-se a necessidade de explicar o que se entende por lingüística e como se define ciência.

A busca de um ideal científico, com uma metodologia eficaz e capaz de garantir alguns resultados objetivos e gerais, parece ter sido a maior pretensão do positivismo e do descritivismo. Auguste Comte, de um lado, propôs uma filosofia social baseada na observação e na descoberta das leis (sociais) para a previsão e, na medida do possível, para a alteração dos fatos (sociais). Seu objetivo era fazer com que a política se aproximasse das chamadas "ciências naturais" - astronomia, física, química e fisiologia. Seu ideal científico era o que ele denominava de "positivo", aquele baseado na observação e na descrição das leis que regem os fatos sociais, sem se preocupar com a busca das causas.

Do outro lado, Leonard Bloomfield, numa visão bastante parecida, aplicou a teoria estruturalista de Saussure nos Estados Unidos de modo muito particular, privilegiando a descrição das leis do sistema lingüístico. De Saussure, ele herdou basicamente o fazer lingüístico sincrônico. Dos lingüistas americanos que o antecederam, Bloomfield recebeu a influência de um estudo voltado especialmente para as línguas ameríndias. Ele utilizou a teoria behaviorista e analisou a língua como um sistema em que os elementos se organizam por um certo comportamento geral.

O que acontece, no entanto, é que a forma de observar e descrever os chamados "comportamentos" do sistema lingüístico era muito próxima da teoria positivista. Dessa forma, o que une os positivistas e os descritivistas é a busca de uma metodologia que lhes reserve o direito de serem chamadas de "ciência".

Por esse motivo, propus-me a escrever este artigo, visando comparar as duas correntes, a partir das seguintes perguntas: que características positivistas são identificáveis na lingüística descritivista de Bloomfield? Há diferenças e divergências entre esses dois tipos de pensamento? Para tentar responder essas indagações, o artigo apresenta uma visão geral do positivismo e do estruturalismo. Em seguida, faz um levantamento das idéias descritivistas, comparando-as as idéias positivistas e, por fim, apresenta algumas críticas feitas à escola de Bloomfield, que antecedeu a de Chomsky.

\section{0 positivismo}

\subsection{Precedentes históricos}

As raízes positivistas nascem muito antes do século XIX. Um exemplo é o fenomenalismo, que acreditava na aquisição do conhecimento por meio da sensação. Reale e Antiseri (2003) dizem que essa foi uma idéia usada por duas das mais antigas escolas filosóficas da Grécia antiga: o epicurismo e o estoicismo (séculos IV e III a.C.). Kolakowski (1972) afirma que, no século XIII, o inglês Francis Bacon, bastante citado por Comte, posicionou-se favoravelmente ao controle técnico, numa tentativa de mostrar que o valor do conhecimento poderia ser medido por efeitos e aplicações. Galileu Galilei aparece no século XVII e é referência na formulação de um programa fenomenalista de conhecimento. Para ele, descrições prévias do mundo eram capazes de atribuir as causas de fenômenos observados para coisas (fatos) não-empíricos (o peso, por exemplo, como a causa da queda dos corpos).

Kolakowsky (1972) vê em David Hume, filósofo inglês, o verdadeiro "pai” da filosofia positivista. Foi ele quem propôs uma divisão das percepções da mente em impressões e idéias. Estas derivam daquelas, como cópias. Saber da existência das propriedades das coisas, não nos dá a certeza da causalidade. Ou seja, o conhecimento não é dado a priori, mas está na conexão entre causa e efeito; conhecimento que só é possível pela experiência, ou seja, a posteriori. Isso fará Hume assumir um argumento contrário à causalidade e à ordem da natureza ${ }^{2}$.

\subsection{Contexto de surgimento}

Ribeiro Jr. (1996), diz que o século XIX marca o triunfo do liberalismo e do cientificismo. O primeiro afirmava que o desenvolvimento da sociedade, fosse

\footnotetext{
${ }^{2}$ Ao leitor interessado na contestação de Hume sobre a causalidade, recomendo a leitura de Aspectos da crítica de Hume ao princípio de causalidade, Pinto (1995).
} 
ele moral, cultural político ou econômico, só aconteceria pelo livre progresso do espírito e das faculdades pessoais. Isso resultava na valorização pessoal precedendo as condições históricas, políticas, sociais, culturais e promovendo uma igualdade entre indivíduos. Dessa forma, até mesmo o Estado vinha depois do indivíduo, o grande privilegiado na relação.

Essa estrutura liberal, dada a priori, transformou-se quando em contato com o empirismo e o materialismo. Para esta corrente, o conhecimento poderia ser reduzido "aos dados da experiência sensível”. (Op. cit., p. 12). Já para o materialismo, "a matéria e suas leis são tudo o que existe, ou a explicação de tudo". (Ibidem). Assim, ciência e pensamento político-social passaram a valorizar o empirismo em detrimento do uso autoritário da razão e surge o cientificismo, condenando a visão apriorística liberal e propondo o conhecimento dos fatos pela experiência dos sentidos.

O positivismo, que surgiu na França por meio de Isidore-Auguste-Marie-Xavier Comte, é resultado disso tudo, uma filosofia que domina o pensamento do século XIX, como método e como doutrina.

[Seu método era baseado] na certeza rigorosa dos fatos da experiência; [sua doutrina] apresentava-se como revelação da própria ciência, ou seja, não apenas regra por meio da qual a ciência chega a descobrir e prever (isto é, saber para prever e agir), mas conteúdo natural de origem geral que ela mostra junto com os fatos particulares, como caráter universal da realidade. (Idem, p.13).

O método e a doutrina não existiam, no entanto, para procurar as “causas” dos fatos, mas para buscar as "leis" que regia os fatos. O próprio Comte afirma que o positivismo substitui as causas pelas leis. O método a posterior - reafirmando a proposta cientificista - pretendia “observar” ou descrever o mecanismo do mundo.

\subsection{O desejo positivista: descrever $\mathrm{e}$ prever}

Auguste Comte busca um novo sistema social que seja regido pela ciência, ou que, pelo menos tenha um caráter científico. Para isso, é preciso que "os sábios elevem a política à categoria de ciência de observação" (COMTE, s/data, p.157). Ele estava seguro de que, para atingir o estado de ciência, uma doutrina (disciplina) precisa passar por três estágios, pelos quais todos nós também passamos no percurso da nossa vida: estado teológico, estado metafísico e estado científico ou positivo.

No estado teológico ou fictício é onde se recorre às idéias sobrenaturais. Os fatos observados são explicados, mas por meio de fatos já vistos a priori. É o estado de qualquer ciência em sua gênese. Por ser a única forma de relacionar idéias na primeira fase da ciência, embora primitivo, é essencial, indispensável para o progresso.

O estado metafísico ou de abstração é o estado de transição entre o fictício e o positivo, pois liga os fatos com idéias que não são sobrenaturais nem positivas por completo.

Por fim, o estado científico ou positivo é o modo definitivo a que pode chegar uma ciência qualquer. Os estados anteriores não formularam a verdade, mas prepararam o terceiro. Os fatos se ligam por idéias ou leis gerais, mas agora de ordem positiva, ou seja, sugeridos ou confirmados por fatos da mesma ordem. Há sempre que se observar os fatos como meios de expressão geral para cada ordem de fenômenos.

Comte (s/ data, p.9) diz que se verificando a história das ciências será possível perceber a exatidão deste esquema para "as quatro ciências fundamentais que hoje são ciências positivas: a astronomia, a física, a química e a fisiologia" e outras a elas relacionadas. As quatro ciências positivas têm caráter físico: física celeste (astronomia) e a física terrestre (demais). Falta, portanto, uma física social. Comte incumbe a si mesmo o papel de fazê-la.

Kolakowsky (1972) afirma que, para Comte, as leis do desenvolvimento do conhecimento humano são históricas. A partir das leis, a evolução humana tem estágios necessários (os três estados) e não “erros”. As leis (sociológicas e históricas) dessa evolução têm a sua própria racionalidade, seu próprio desenvolvimento. As idéias desses estágios são verdadeiras ou, pelo menos, necessárias para a sua época.

O que se percebe, portanto, é que Comte está imbuído no desenvolvimento de uma filosofia que conceitua ciência basicamente como sinônima ao materialismo, isto é, ele quer ser preciso em suas definições e restrições. Tal postura resulta na delimitação de duas classes de ciências naturais. 
Umas são abstratas, gerais, que têm por objeto a descoberta das leis que regem as diversas classes de fenômenos e que consideram todos os casos possíveis de conceber; outras, concretas, particulares, descritivas ${ }^{3}$, designadas algumas vezes sob o nome de ciências naturais propriamente ditas e que consistem na aplicação dessas leis à história efetiva dos diferentes seres existentes. As primeiras são fundamentais, sendo a elas que, neste curso nossos estudos se limitarão. As outras, seja qual for sua importância, são de fato apenas secundárias. (COMTE, s/data, p.25).

Comte dita a metodologia de busca da classificação natural, abstrata e geral: "para obter uma classificação é preciso procurar seu princípio na comparação das diversas ordens de fenômenos, cujas leis têm por finalidade descobrir. (...) Deve-se começar dos mais simples aos mais complexos”. (Idem, p.30).

Deste modo, a busca das causas das leis sociais é inútil para Comte. O que sua filosofia propõe é a tomada dos fatos sociais como sujeitos a leis que devem ser observadas a fim de descrever os contextos que as produzem.

[O caráter da filosofia positivista] é tomar todos os fenômenos como sujeitos a leis naturais invariáveis, cuja descoberta precisa e cuja redução ao menor número possível constituem o objetivo de todos os nossos esforços, considerando como absolutamente inacessível e vazia de sentido para nós a investigação das chamadas causas, sejam primeiras, sejam finais. (...) Pretendemos somente analisar com exatidão as circunstâncias de sua produção e vinculá-las umas às outras, mediante relações normais de sucessão e similitude. (COMTE 1983, p.7).

Alguns estudiosos do positivismo dizem que, na realidade, essa filosofia não busca as causas por não acreditar na possibilidade do conhecimento delas: "[causes] are occult entities that are by definition inaccessible to human knowledge". (KOLAKOWSKI, 1972, p.12). Além disso, a crença dos positivistas era a de que os métodos eram os mesmos paras as diversas experiências: "the methods for acquiring valid knowledge, and the main stages in elaborating experience through theoretical reflection, are essentially the same in all spheres of experience”. (Op. cit., p. 17).

Auguste Comte, para reafirmar o caráter essencialmente explicativo de sua filosofia, lembra que a lei de Newton sobre a gravitação universal é a representação de um fenômeno já conhecido: a gravidade dos corpos na superfície da terra. Não importa buscar a causa disso. A filosofia positiva considera isso como insolúvel e deixa a busca das causas para "a imaginação teológica e para a sutileza metafísica”. (COMTE, 1983, p. 7).

A política então, deveria evoluir para o estado científico porque, pela observação dos fatos e não pela busca das causas, seria possível fazer previsões e desenvolver o coletivo. Ele diz também que a eficácia científica resulta exclusivamente da observação dos fenômenos e resulta da revolução positiva, que "consiste essencialmente em substituir sempre a inacessível determinação das causas propriamente ditas, pela simples investigação das leis, isto é, pelas relações constantes que existem entre os fenômenos observados”. (COMTE, s/data, p. 174).

Ele insiste ainda que tal observação deve ajudar o positivista a fazer previsões racionais e "assim, $o$ verdadeiro espírito positivo consiste, sobretudo, em ver para prever, em estudar aquilo que é, a fim de concluir, a partir daí, aquilo que será”. (Idem, p. 177).

Uma conseqüência esperada pela filosofia positiva na aplicação política (poderíamos dizer ainda pela “política positiva”) é promover a reforma do sistema de educação europeu, priorizando o ensino das generalidades e do enciclopedismo. Isso ajudaria não apenas aos alunos, mas também ao progresso das ciências positivas. Ainda no âmbito social, Comte confiou à sua filosofia o papel de alicerce da reorganização da sociedade, reorganização essa que deve terminar com a crise do estado, na qual se encontram as nações mais civilizadas.

A observação é essencial para previsões racionais que, por sua vez, devem resultar em ações, sempre em benefício do homem: “o conhecimento das leis dos fenômenos, cujo resultado constante é fazer com que sejam previstos por nós, evidentemente pode nos

\footnotetext{
${ }^{3}$ Certamente aqui o que Comte define como “descritiva” não pode ser atribuído à lingüística de Bloomfield, cujo caráter era, como o positivismo, o de uma ciência abstrata e geral.
} 
conduzir, de modo exclusivo, na vida ativa, a modificar um fenômeno por outro, tudo isso em nosso proveito". (COMTE, 1983, p. 23).

\section{0 estruturalismo}

\subsection{O fazer científico e o estruturalismo}

De certa forma, considera-se o início do estruturalismo, como movimento lingüístico, a publicação do Cours de linguistique générale, de Ferdinand Saussure, em 1916. Nesse livro, publicado postumamente ${ }^{4}$, Saussure propõe que se investigue "de que maneira todas as formas e sentidos estão inter-relacionados num determinado sistema lingüístico, em determinado ponto do tempo". (LYONS, 1987, p. 203). Era uma contraposição ao historicismo, escola precedente, que afirmava ser a lingüística uma disciplina científica e, portanto, necessariamente histórica.

As propostas saussureanas ganharam força e contribuíram para o estabelecimento da lingüística como disciplina científica ou, pelo menos, em suas adaptações pelos diversos seguidores, passou a desenvolver uma metodologia bem próxima do que se creditava a uma ciência.

O início do século XX, diz-nos Lyons (1987), marcou discussões sobre o fazer cientifico, especialmente a respeito da metodologia a se utilizar para que uma disciplina fosse verdadeiramente científica. Face a isso, o estruturalismo desenvolvido pelo norte-americano Leonard Bloomfield orientou o lingüista a fazer uma pesquisa verdadeiramente científica, devendo, o lingüista, assumir uma posição de empirista e positivista em relação ao fato observado.

Lyons (1987) apresenta também dois princípios que regulamentavam a ciência desse período: princípio da verificação, pelo qual toda formulação científica, para ser realmente científica, deveria passar pelo crivo da observação (empirismo de Hume) e o da redução, que propunha uma hierarquia entra as ciências, das mais básicas para as outras (a física e a química eram as mais básicas que a biologia, por exemplo) e que os conceitos e afirmações das ciências mais básicas po- deriam ser utilizados pelas outras ciências (tese positivista).

Falando sobre os estruturalistas americanos anteriores à década de 50 (pré-Chomsky), Ilari mostra que a crença deles era a de que

a tarefa que todo lingüista deveria enfrentar [era] a constituição de um corpus de sentenças ou textos da língua [em estudo] em seguida, obedecendo à orientação de Bloomfield, imaginavam algum processo indutivo de generalizações sucessivas que poderia reduzir o corpus a uma representação compacta. (ILARI, 2004, p. 78).

Mas para autores como Gleason, essas generalizações garantiam o estabelecimento da lingüística como ciência, à medida que mostravam a estrutura da língua: "[a lingüística] é a ciência da linguagem que procura compreender a linguagem da perspectiva da sua estrutura”.(GLEASON,1978, p.32). Ele continua dizendo que, por esse caráter, a lingüística desenvolveu um método próprio, altamente eficaz e característico, que influenciou inclusive outras disciplinas. Mesmo tendo que recorrer, por vezes, à outras ciências, como a física acústica, o método estruturalista é singular.

\subsection{Estrutura e sistema}

São vários os conceitos conhecidos em lingüística que foram inaugurados e/ou amplamente utilizados pelo estruturalismo ${ }^{5}$. Entre os mais importantes estão os de estrutura e sistema e, para apresentá-los, valhome de uma explicação dada por Borba, que compara a língua com o sistema solar.

Dizemos que um conjunto de objetos constitui um sistema quando esses mesmos objetos se aproximam por terem alguns traços em comum e se organizam seguindo determinados princípios de tal modo que o resultado seja um todo coerente. Por exemplo, o sistema solar é formado por um conjunto de astros - o sol, os planetas, os satélites, os asteróides -, que seguem determinadas leis da mecânica celeste: os satélites giram em torno dos planetas, e estes, em torno do sol; planetas e satélites giram também em torno do próprio eixo etc. o que caracteriza o sistema é o arranjo de seus compo-

\footnotetext{
${ }^{4} \mathrm{O}$ livro foi organizado por alunos de Saussure que juntaram as anotações das aulas do mestre. Muitos quiseram tirar o crédito da obra por causa disso. Ver Ilari (2004).

${ }^{5}$ Ao leitor interessando nesses conceitos, recomendo os textos de Lepschy, Ilari e Lyons.
} 
nentes e, depois, os princípios que determinam tal arranjo. Digamos que a esse arranjo se dê o nome de estrutura; então, uma estrutura vem a ser a disposição dos elementos dentro de um sistema, o que vale dizer que é fundamental para a existência do sistema. (BORBA, 1991, p.29).

Essa é uma explicação para as idéias de estrutura e sistema. Ao ler, por exemplo, Harris (1951), essa noção de arranjo de elementos em um sistema, formando a estrutura, é de uma similaridade muito grande.

Nesses conceitos reside uma diferença entre o chamado estruturalismo europeu, de orientação saussureana e o americano, de orientaçãobloomfieldiana. Benveniste (1988) diz que a palavra estrutura, definida como sistema, é própria do estruturalismo europeu e que, para o estruturalismo americano, a idéia é de distribuição dos elementos, tal como se verifica, e a sua capacidade de associação ou de substituição. E tece uma crítica: para o autor, esses esquemas de distribuição, por mais rigorosos que sejam, não mostram uma estrutura da língua, assim como o inventário de fonemas e morfemas não representam a descrição de uma língua. Benveniste diz que "o que nos representam, efetivamente, é um método de transcrição e de decomposição material aplicado a uma língua que seria representada por um conjunto de textos orais e cuja significação o lingüista ignoraria". (BENVENISTE, 1988, 11-12).

Gleason (1978) diz que a linguagem funciona com duas espécies de material. Para o autor, quase toda a variedade de sons que o aparelho vocal humano produz é utilizado por alguma língua. Portanto, o primeiro material da língua é o som. O segundo material consiste basicamente nas idéias, situações sociais e significado. Já que o lingüista ocupa-se do som como meio de transmissão da informação, ele deve analisar a linguagem como uma seqüência ordenada de certas espécies de sons.

Essa definição é bastante descritivista. Autores como Harris (1951) propõem uma metodologia pela qual o lingüista deve buscar as relações de distribuição (seqüência ordenada) dos sons (e morfemas) na língua: "the linguist, then, investigates the distributional relations among the elements". (HARRIS, 1951, p.8). É essa distribuição (arranjo) dos elementos do sistema que a lingüística descritiva procura.

\subsection{O estruturalismo norte-americano}

Ilari (2004) dá-nos uma idéia do que foi o avanço do estruturalismo pelas diversas áreas da lingüística depois de Saussure. O autor apresenta diversas esferas do ramo lingüístico, como a sintaxe e a semântica, que receberam o adjetivo estrutural. Para Ilari, a inserção desse adjetivo era mais uma prova do prestígio do estruturalismo do que propriamente uma forma de identificar o conteúdo da obra. Para alguns autores, como Raffaele Simone, apud Ilari (2004), Saussure promoveu não uma teoria lingüística, mas uma metateoria, que apresentava noções válidas e adequadas a diversas teorias.

Lançado nos anos 50, o manual de lingüística descritiva de Gleason comentava a importância da linguagem para outras disciplinas e a inserção da disciplina de lingüística descritiva no currículo de diversas universidades americanas. Eram, segundo ele, inúmeras pessoas atraídas pela lingüística.

Há problemas humanos importantes nos quais a linguagem se imiscui tão intimamente, exercendo sobre eles uma influência tão profunda, que a compreensão do seu mecanismo contribuiria materialmente para a solução daqueles. (GLEASON, 1978, p.1).

Nesse caminho, o que chamamos "estruturalismo” ganhou uma série de adeptos em solo norte-americano. Franz Boas, da escola neogramática do início do século XX e especialista em línguas ameríndias, iniciou uma obra chamada Handbook of American Indian Languages. De Boas, o descritivismo herdou o interesse pelo estudo das línguas ameríndias.

A partir da segunda década daquele século, a lingüística estruturalista norte-americana foi ganhando força, sempre a preocupação de descrever as línguas sincronicamente. Isso se deveu graças às exigências requeridas pelas línguas ameríndias e pela busca do ensino e aprendizagem das línguas desconhecidas (especialmente as ditas “exóticas”) - Lepschy (1975) diz também que o progresso das telecomunicações também influenciou o estruturalismo norte-americano.

Mas foi com Edward Sapir que o estruturalismo norte-americano decolou. Conhecedor de lingüística, literatura, antropologia e música (entre outras áreas), é chamado por Lepschy (1975, p. 81) de "o mais humanista dos lingüistas estruturalistas norte-americanos”. Para Sapir, o “fato lingüístico” era comple- 
xo e variado, o que exigia cautela ao se falar da estrutura de uma língua. Seus conhecimentos nas diversas áreas impedem que ele seja um simplista na definição de estrutura. Diz Lepschy:

\begin{abstract}
É necessário notar a prudência e o equilíbrio com os quais ele fala da estrutura lingüística, evitando excessivas exemplificações e o fácil cientificismo que, a seguir, tornaram-se tão freqüentes. (...) Desde o prefácio, ele insiste sobre o caráter 'inconsciente e sobre a natureza não-racionalista' da estrutura lingüística. (LEPSCHY, 1975, p.82).
\end{abstract}

Sapir, no entanto, não faz grandes considerações sobre o som. Diz que a língua deve ser construída por um número relativamente pequeno de sons distintos, mas não estabelece a noção de fonema, hoje bastante difundida. Apenas em um artigo de 1925, intitulado Sound patterns in language, aparece a noção de "fonema", inclusive falando sobre um "som fundamental" e "variantes desse som". Em um artigo de 1933, The psychological reality of phonemes, é possível encontrar a definição de Sapir para fonema: "é unidade funcionalmente significante na rigidamente definida configuração dos sons, peculiar a uma língua”. (SAPIR, apud LEPSCHY, 1975, p. 85). O lingüista americano não acredita serem necessários "métodos rigorosos e objetivos, mecanicamente aplicáveis, que permitam controlar e verificar o quanto ele afir$m a$ ”. (Op. cit., p.86). Essa posição, associada à psicologia mentalista, é contrária à de Bloomfield, cuja orientação segue a linha do behaviorismo.

Embora não se deva negar a influência de Saussure na lingüística dos Estados Unidos, foi especialmente em Leonard Bloomfield que os estruturalistas de lá encontraram sua maior referência.

\subsection{O descritivismo de Bloomfield}

Saussure foi um pesquisador que não desprezou a lingüística histórica. Ele mesmo fez um trabalho importante sobre o proto-indo-europeu. No entanto, Ilari (2004) e Lepschy (1975) dizem que ele passou a se preocupar com a estrutura sincrônica das línguas. Lepschy (1975) afirma também que Bloomfield não poupava críticas aos tradicionalistas, já que seu objetivo era praticar um método verdadeiramente "científico" para a linguagem.

No capítulo de abertura do Language,
Bloomfield (1961) mostra algumas discussões e tratamentos dados à língua ao longo do tempo. Para ele, a gramática da Índia (cerca de 350 a 250 a.C.), baseada na observação e na descrição do Sânscrito, foi o primeiro grande trabalho desse tipo que apareceu na Europa e possibilitou o estudo comparativo das línguas. Por isso, exalta o árduo trabalho dos pesquisadores do século XIX que se empenharam tanto (e com êxito) na comparação das línguas, chegando, por exemplo, ao Proto-indo-europeu.

No entanto, não obstante a alta qualidade dos trabalhos, pelo estudo histórico e comparativo não se pode ir muito longe. Esses trabalhos possuem uma série de noções filosóficas que não nos são muito familiares: "for the most part, however, descriptive studies did not merge with the main stream of historical work. (...) In fact, much of the older descriptive work is almost unintelligible today because it is pervaded by philosophical notions that are no longer familiar to us". (BLOOMFIELD, 1961, p.18).

Bloomfield, na adoção de uma nova perspectiva na lingüística, elogia o trabalho de Wilhelm Wundt (1832-1920), que se baseia na psicologia para descrever a fala humana: "Wundt based his psychology of speech upon any and all accessible descriptions of languages”. (Ibidem).

Antes do século XIX, ou a filosofia organizava o estudo da língua, ou a descrição era muito restrita. É por isso que, para Bloomfield (1961), foi apenas no século XIX que surgiram algumas teorias lingüísticas capazes de ser consideradas realmente científicas pelo seu método descritivista e buscando características gerais da língua: "It is only within the last century or so that language has been studied in scientific way, by careful and comprehensive observation." (BLOOMFIELD, 1961, p.3).

Lyons (1987) afirma que Bloomfield, apesar de valorizar os estudos históricos da linguagem, critica o caráter "mentalista, pseudo-explicativo e psicológico desses estudos” e propõe uma substituição disso pela "generalização indutiva, com base no estudo descritivo da linguagem”. Nessas contestações nasce o descritivismo bloomfieldiano (ou americano, ou lingüística descritiva). Lyons (1987) confirma que o descritivismo é considerado a versão norte-americana do estruturalismo europeu. 
A obra de Bloomfield que marca o início do descritivismo é Language, de 1933, que, segundo Lepschy (1975), foi considerado o maior livro de lingüística do século, nas décadas seguintes à publicação. Além disso, a exposição dos métodos bloomfieldianos fez com que se pudesse considerar uma lingüística pós-bloomfieldina nos Estados Unidos, pelos menos nos 20 anos seguintes ao lançamento.

Bloomfield utiliza a concepção mecanicista do comportamentismo (behaviorismo) para os fatos lingüísticos. Ele entende que "o funcionamento da sociedade humana deve-se à linguagem" (LEPSCHY, 1975, p. 89), pois os eventos extra-lingüísticos podem ser substituídos por um ato lingüístico. É uma espécie de estímulo-resposta e o que há entre o locutor e o interlocutor são apenas ondas sonoras. Bloomfield diz que

entre o indivíduo e a sociedade há uma relação análoga àquela entre a célula e o animal pluricelular; assim como essa relação é possível, no animal, pelo sistema nervoso, do mesmo modo ela é possível, na sociedade, pela língua, ou melhor, pelas ondas sonoras. (Apud LEPSCHY, 1975, p. 90)

Para Bloomfield as idéias, conceitos, imagens não são mentais, mas apenas movimentos corporais. Assim, o “pensar em palavras” é substituído pelos movimentos silenciosos dos órgãos vocais. Essa escolha mecanicista considera a variabilidade do comportamento humano à complexidade do corpo humano. O sistema nervoso é que comanda a linguagem, pois a estímulos (sons quaisquer) podemos dar respostas bastante complexas.

Essa escolha pelo comportamentismo éuma tentativa de Bloomfield de seguir aquela escola que, para ele, tinha as explicações mais científicas para os comportamentos do universo. E é uma atitude defendida pelos seus seguidores. Vejamos, por exemplo, o que diz Harris:

It is possible, of course, to study speech as human behavior, to record the physiological motions which are involved in articulation, or the cultural and interpersonal situation in which the speaking occurs, or the sound waves which result from the activity of talking, or the auditory impressions gained by the hearer. We could try to state regularities in the description of each of these bodies of data. (HARRIS, 1951, p. 4).

Bloomfield entende que, na descrição, o lingüista deverá mostrar o papel dos diferentes elementos da língua.

Não se deverá, portanto, recorrer a uma descrição pu-
ramente física (negligenciando os traços acústicos que
aparecem como ‘os mesmos’ e como ‘diferentes’), e
nem a uma lista que leve em conta apenas os traços
distintivos; será necessário, preferivelmente, demons-
trar os ‘fatos estruturais’, isto é, ‘o papel que os dife-
rentes fonemas representam no funcionamento da lín-
gua’. (Apud LEPSCHY, 1975, p. 95).

Um dos exemplos mais marcantes utilizados por Bloomfield para expor sua teoria é a distinção que ele faz para “atos de fala” e “eventos práticos”. Imagine, por exemplo, um casal andando por uma estrada

(a) a moça sente fome e vê uma goiaba;

(b) ela faz um ruído com a sua laringe, sua língua e seus lábios.

(c) Ele pula a cerca, sobe na árvore, pega a goiaba e dá nas mãos da moça.

O evento (a), em que é possível haver toda uma reação física e fisiológica do corpo da moça mostrando que está com fome (o estômago roncando, por exemplo), é o estímulo do falante. O evento (c) é a resposta do ouvinte - (a) e (c) são eventos práticos. Por fim, o evento (b) é o ato de fala, que pode ser estudado graças aos avanços da física e da fisiologia.

Para Bloomfield o evento (b), o ato de fala, nada mais é que a ação do falante substituída pela fala. Em outros termos, a moça poderia pegar a goiaba e resolver o problema da fome, fazendo, portanto, um evento prático. Ela daria um estímulo e ela mesma responderia a esse estímulo. A fala substitui essa ação.

Mas, como saber que resposta o ouvinte dará ao estímulo?

A escolha por uma resposta específica ao estímulo também foi uma questão abordada por Bloomfield. Para ele, a teoria mentalística baseia-se no espírito (ou na mente). O espírito é quem decidirá a resposta ao

\footnotetext{
${ }^{6}$ Exemplo integral em Bloomfield (1961, p. 22-26).
} 
estímulo.A teoria mecanicista, afirmará Bloomfield, diz a variabilidade da conduta humana (inclusive a fala) acontece graças à complexidade do corpo humano. As ações humanas são parte das “seqüências” de causa e efeito, como na física ou na química. Mas, pela complexidade, o corpo humano é uma estrutura mutável. E o sistema nervoso é o responsável pela mutação: causa-efeito versus estímulo-resposta. É por isso que não é possível saber que reposta um ouvinte dará a um estímulo.

É a partir daí que nasce a tendência bloomfieldiana em privilegiar o estudo observacional, descritivo e mecânico da língua, especialmente de língua não-escritas. Corneille expõe a atitude de abandono da metafísica e da filosofia por parte dos descritivistas.

Confrontando-se com línguas não escritas, sem passado conhecido, e que na sua maioria não tinham ainda sido estudadas, os predecessores de Noam Chomsky impõem-se um objectivo essencialmente prático: descrever o maior número de idioma possível com o máximo de rigor e eficácia possíveis. (CORNEILLE, 1982, p. 26).

\subsection{O desejo descritivista: descrever e prever}

Seguidores da escola bloomfieldiana passaram a lançar manuais e livros que divulgam as idéias do descritivismo. Entre os mais importantes destes seguidores está Zellig Harris. Em seu livro de 1951, é possível ver, por exemplo, a idéia da busca descritivista pelas regularidades na língua. Era o desejo de, a partir da observação, encontrar as leis que regulam o funcionamento da língua, ou, a distribuição dos elementos que a formam.

Descriptive linguistics, as the term has come to be used, is a particular field of inquiry which deals not with the whole of speech activities, but with the regularities in certain features of speech. These regularities are in the distributional relations among the features of speech in question. (...) The main research of descriptive linguistics, and the only relation which will be accepted as relevant in the present survey, is the distribution or arrangement within the flow of speech of some parts or features relatively to others. (HARRIS, 1951, p.5).

\section{A lingüística descritiva deve ter como universo}

de trabalho uma língua, especificamente, sem buscar uma descrição única para todas as línguas. Aliás, numa mesma língua, pode haver dialetos que tenham regularidades diferentes entre os elementos. Portanto, "the universe of discourse for a descriptive linguistics investigation is a single language or dialect." (Op. cit., p. 8).

Mas no descritivismo, é preciso que as falas (utterances) do corpus de uma língua em análise sejam capazes de mostrar a regularidade de todas as falas da língua: "Investigations in descriptive linguistics are usually conducted with reference to any number of whole utterances. Many of the results apply explicitly to whole utterances." (Idem, p. 11).

Para os descritivistas, um corpus de análise bem definido pode mostrar não só as regularidades da língua para aquelas falas escolhidas, mas é uma amostragem da língua como um todo. Assim, as regularidades do corpus são as regularidades da língua e a distribuição dos elementos nas frases do corpus será a mesma para aquelas que estão fora dele. Em outras palavras, escolher algumas falas não é manipular a análise ou não dar conta das falas não analisadas. Essa é a questão da previsão, que decorre do método dedutivista. Nas três passagens seguintes, Harris confirma:

To persons interested in linguistics results, the analysis of a particular corpus becomes of interest only if it is virtually identical with the analysis which would be obtained in like manner from any other sufficiently large corpus of material taken in the same dialect. If it is, we can predict the relations among elements in any other corpus of the language on the basis of the relations found in our analyzed corpus. When this is the case, the analyzed corpus can be regard as a descriptive sample of the language. (HARRIS, 1951, p.13).

This does not mean that other sequences of these elements, or other elements, do not occur; they may have occurred without entering into our records, or they may have not yet occurred in any utterance of the language, only to occur the next day. Aside from this, however, we may also be able to say that certain sequences almost never occur; we may know this from direct testing, or from the fact that the sequences goes counter to the most general regularities of our corpus. (HARRIS, 1951, p. 372).

The work of analysis leads right up to the statements which enable anyone to synthesize or predict utterances in the language. These statements form a deductive system with axiomatically defined initial 
elements and with theorems concerning the relations among them. The final theorems would indicate the structure of the utterances of the language in terms of the preceding parts of the system. (Ibidem).

Harris diz que, se o lingüista consegue definir os elementos da língua (fonológicos e morfológicos), a língua será representada pela descrição das regularidades e das relações que existem entre os elementos definidos.

Once the elements are defined, any occurrence of speech in the language in question can be represented by a combination of theses elements, each element being used to indicate the occurrence in the speech of a feature with which the element is associated by its definition. It is then possible to study these combinations (mostly, sequences) of elements, and to state their regularities and the relations among the elements. (HARRIS, 1951, p.17).

Todo esse trabalho de descrição e previsão poderá gerar uma gramática descritiva da língua em estudo. Gramática essa que nada mais é que a descrição (e não prescrição!) das regras daquela língua. Explicanos Gleason.

Se o lingüista conseguir uma generalização adequada a partir do seu corpus terá produzido uma gramática descritiva. (...) Uma gramática descritiva adequada proporciona uma descrição para qualquer frase da língua. Esta descrição é uma seleção de regras que, quando bem combinadas, definem um esquema básico que se pode considerar exemplificando por uma frase dada. (GLEASON, 1975, p.214).

Em verdade, o próprio Bloomfield criticava o ensino prescritivo nas escolas e a rejeição às variantes. Sua abordagem descritiva foi uma reação a isso, uma forma de defender as variantes da língua como parte da língua e não uma língua errada ou estranha. Para ele, o normativismo que envolve as gramáticas escolares vem desde a época dos filósofos medievais. Ele argumenta:

The undesirable variants are not foreigners errors, but perfectly good English; only, they are not used in the speech of socially more privileged groups, and accordingly have failed to get into the repertory of standard speech-forms. (BLOOMFIELD, 1961, p. 496).
Completa dizendo que a atitude de definir um dialeto como melhor que o outro é autoritarismo.

Our unfortunate attitude toward matters of standard and non-standard speech ("correct English") is largely kept up by our schools. Their attitude is authoritarian; fanciful dogmas as to what is "good English" are handed down by educational authorities and individual teachers who are utterly ignorant of what is involved... (BLOOMFIELD, 1961, p. 500).

Bloomfield privilegia o estudo da fala, dos sons da língua, porque acredita que é nela que se pode identificar a distribuição dos elementos da língua. Além disso, os dialetos de uma língua, podem ter uma distribuição diferente dos elementos da fala, mas têm uma escrita igual. O estudo da escrita é indispensável, diz ele, mas é papel de outras abordagens estudar isso (o estilo de uma pessoa) e não da lingüística. A literatura, por exemplo, pode estudar o estilo de Shakespeare. Por outro lado, "the linguist studies the language of all persons”. (BLOOMFIELD, 1961, p. 22). Não é função do lingüista analisar se algo é "bonito, correto" ou “feio, incorreto” na língua. Os lingüistas devem preocupar-se mesmo com a observação normal da fala. Langacker (1977) dirá ainda que a preocupação com a fala é uma herança deixada pela lingüística histórica aos estruturalistas americanos.

\subsection{Noções de fonema e de significado para o descritivismo}

A descrição dos elementos de uma língua, para o descritivismo, deve mostrar quais elementos dela são distintivos e quais não são. A idéia de distribuição passa antes por essa análise e a noção do que é fonema numa determinada língua é essencial para uma descrição eficaz. E aqui, Bloomfield avança nos estudos dos sons, que para outros lingüistas americanos anteriores foi um estudo um pouco vago (por exemplo, para Sapir).

Fonema, para Bloomfield (1961), é uma parte da língua conectada com o significado e essencial para a comunicação. Nisso está a noção de distintividade, em oposição à de não-distintinvidade numa língua, que complicam a posição do lingüista. Se ele trabalha especialmente com línguas que não conhece, que não são 
a sua, como saber se um elemento da língua em estudo é ou não distintivo? Ele diz que nesse caso os estudos acústicos não serão suficientes para dizer se um determinado elemento é ou não distintivo na língua. Encontrar essa distintividade só será possível se a lingüística simular um progresso científico capaz de identificar a composição do significado das falas da língua, utilizando o método de tentativa e erro ou contando com a colaboração de alguém que conheça a língua em estudo.

To recognize the distinctive features of a language, we must leave the ground of pure phonetics and act as though science had progressed far enough to identify all the situations and responses that make up the meaning of speech-forms. (...) In the case of a strange language we have to learn such things by trial and error, or to obtain the meaning from someone that knows the language. (BLOOMFIELD, 1961, p. 77).

Isso fez com que a lingüística, a partir de Bloomfield, fizesse uma diferença entre fonética - que estuda a estrutura acústica do som e pode ajudar na identificação dos sons, mas não é suficiente para isso e fonologia - que define as unidades distintivas, chamadas de fonemas e, por isso, leva em consideração os significados.

Sobre significado de uma forma lingüística (meaning), Bloomfield (1961) diz ainda que o pesquisador deve defini-lo como a situação em que o falante pronuncia algo e o ouvinte responde. Em outras palavras, deve ser entendido a partir da visão behaviorista do estímulo-resposta. Mas ele faz uma ressalva: os significados dados pelas diversas ciências aos seus objetos, são variados e imprecisos, por isso, " the statement of meanings is therefore the weak point in language-study, and will remain so until human knowledge advances very far beyond its present state." (Idem, p.140).

Benveniste (1988) critica Bloomfield e Harris pela negação deles em levar em conta o significado. Para o autor, um dado lingüístico é por si só complexo e entender suas partes não é criar uma teoria para a língua, assim como entender o mundo físico não é condição para se criar uma teoria do mundo físico. Ele afirma também que toda descrição deve supor que o objeto tenha um significado, porque isso é que faz com que a estrutura funcione numa língua.
Há todo um esforço do descritivismo, é verdade, para destituir a lingüística como ciência que estuda os significados. Bloomfield (1961) afirma que é função de outras ciências trabalhar com o significado e não da lingüística. Ele reconhece, então, a limitação do lingüista: "Although the linguist cannot go far toward the explanation of practical things, he has the task of classifying linguistic forms wherever their meaning has been determined by some other science." (BLOOMFIELD, 1961, p. 508). Mas é preciso reforçar que o próprio Bloomfield alega que não trabalha com o significado porque o conhecimento humano não chegou no estado em que isso seja possível, como citado acima. Ele não nega a existência, nega a possibilidade de conhecê-lo.

\section{Positivismo e descritivismo: semelhanças e distâncias}

Parece claro que a primeira semelhança entre Auguste Comte e Leonard Bloomfield é a tentativa de encontrar para seus campos de estudos uma metodologia que seja verdadeiramente científica. Para Comte, a política deve ser positiva, ou seja, observar descrever os fatos sociais para prevê-los e modificálos, se necessário. Ele diz: "[que] os sábios elevem a política à categoria de ciência de observação." (COMTE, s/data, p.157). Para Bloomfield, a lingüística também deve observar, descrever as relações presentes nos fatos lingüísticos e prever essas relações em outras falas da língua. O caráter científico da lingüística está na utilização de seus métodos para descrever o comportamento dos elementos da língua.

The methods and results of linguistics, in spite of their modest scope, resemble those of natural science, the domain in which science has been most successful. It is only a prospect, but not hopelessly remote, that the study of language may help us toward the understanding and control of human events. (BLOOMFIELD, 1961, p. 509).

Com isso, o método vai da indução para a dedução. A partir de alguns fenômenos (sociais ou lingüísticos) o pesquisador pode encontrar as regularidades das leis que governam os fatos da sociedade $\mathrm{e}$ 
da língua e, a partir dessas regularidades, prever as outras ocorrências. O corpus forma uma amostragem. Comte e Harris nos dizem.

O conhecimento das leis dos fenômenos, cujo resultado constante é fazer com que sejam previstos por nós, evidentemente pode nos conduzir, de modo exclusivo, na vida ativa, a modificar um fenômeno por outro, tudo isso em nosso proveito. (COMTE, 1983, p. 23).

Although our whole investigation has been in a particular corpus of utterances, we may consider this corpus to be an adequate sample of the language from which the corpus was taken. With this assumption, the methods of descriptive linguistics enable us to say that certain sequences of certain elements occur in the utterances of the language. (HARRIS, 1951, p. 372).

É necessário, contudo, que se deixe de lado aspectos individuais, particulares, concretos e que se busque uma generalização. O positivismo queria observar os fatos sociais particulares para deles tirar leis gerais (ver item 1.2). O descritivismo também. Embora partisse de um conjunto de falas de indivíduos a busca era sempre por uma descrição geral da distribuição dos elementos da língua. A fala particular de cada um não interessava. Harris é claro: o lingüista não procura o comportamento individual ou inter-pessoal, mas o comportamento geral da língua: "Linguistics sets up a system of relations among selected features of this general behavior [of the language]."(HARRIS, 1951, p. 22).

Não querer buscar as causas dos fenômenos, ou seja, o abandono do apriorismo, é outra característica que aproxima as duas correntes. Comte (ver citação no tópico 1.3) fala que não se deve buscar nem as causas primeiras nem as causas finais, porque isso é inacessível e vazio de sentido. O essencial é observar, é elevar a política à categoria de observação. Joos confirma esse mesmo aspecto no descritivismo.

Se os fatos foram plenamente estabelecidos, é perverso ou infantil reclamar ainda uma explicação. (...) Nós procuramos descrever com precisão, não procuramos explicar. Tudo o que, na descrição, se parece com uma explicação é simplesmente tempo perdido e não deve ser considerado como relevante na teoria lingüística corrente. (JOOS, apud CORNEILLE, 1982, p. 29).

Outra semelhança interessante é que ambos vêem nas ciências naturais (física, química, principalmente) um modelo de análise e uma tentativa de comparação com as disciplinas por eles estudadas. Gleason (1975) diz que os descritivistas, por exemplo, comparavam os fonemas de uma língua aos elementos químicos. Se estes se juntavam para formar as diversas substâncias, era razoável dizer que aqueles se juntavam para formar a língua. Enquanto Comte deu à política o caráter de ciência positiva, ou seja, comparou-a com a física e assumiu a missão de fazer da política uma ciência física, o descritivismo teve características semelhantes, ao menos aos olhos de alguns observadores. Vejase, por exemplo, Langacker (1977, p.14), cujo livro já segue a abordagem gerativista de Chomsky. Para ele, “a lingüística descritiva é, em outras palavras, semelhante à ciência pura [física] e compreende a descrição de uma língua em determinado momento temporal".

A redução é outro ponto de aproximação entre o positivismo e o descritivismo. Comte (1983), citado no item 1.3, diz que o maior esforço do positivismo é a redução das leis descritas pela observação. Ele só não explica como fazer isso, mas é possível interpretar que Comte busca a generalização, já que um número reduzido de leis facilita o trabalho do pesquisador. Os descritivistas, por outro lado, vão propor uma redução com vistas a manter a chamada correspondência "um-a-um”, ou seja, para cada som particular (x), em uma dada posição, é associado um fonema (Y). Harris, por exemplo, dirá que será possível classificar ou substituir os elementos de modo a reduzir o número deles, ou, pelo menos, estabelecer inter-relações com outros elementos: "It is possible to perform upon the elements various operations, such as classification or substitution, which do no obliterate the identificability of the elements but reduce their number or make the statement of interrelations simpler." (HARRIS, 1951, p.17).

Mas o positivismo e o descritivismo têm seus pontos de afastamento. Uma questão interessante em que isso parece estar presente é na constituição do corpus. Comte não faz restrições a que tipo de corpus se deve observar. Para os descritivistas, no entanto, a constituição de um corpus não poderia ser aleatória. Harris (1951) dedica um capítulo todo sobre a ques- 
tão do corpus. Gleason falando sobre a metodologia descritivista dirá que o corpus deve abranger (e não conter) todas as sentenças da língua, reforçando a questão da previsão:

A descrição de um corpus de material deverá comprometer-se a abranger todas as suas frases [da língua], mas apenas essas ${ }^{7}$. É sua função classificá-las relacioná-las entre si (...). Uma vez que ela há-de, necessariamente, incluir muitas frases que o lingüista não observou, a descrição consistirá, assim, uma previsão de frases com cuja ocorrência podemos razoavelmente contar, uma vez dado um estímulo adequado. (GLEASON, 1975, p.209).

Comte também não define alguns elementos dos quais fala, por exemplo, fatos ou fenômenos sociais, que são seus objetos de investigação. Dessa forma, uma pergunta surge: que “objeto” de investigação é esse que não aprece claramente definido? Harris é diferente. A definição parece ser essencial para ele explicar ao investigador o que deve procurar. Os exemplos abaixo são definições de fala (utterance), contexto ou ambiente de ocorrência (environment) e distribuição (distribution).

An utterance is any stretch of talk, by one person, before and after which there is silence on the part of the person. (HARRIS, 1961, p.14).

The environment or position of an element consists of the neighborhood, within an utterance, of elements which have been set up on the basis of the same fundamental procedures which were used in setting up the element in question. (Idem, p.15).

The distribution of an element is the total of all environments in which it occurs, i.e. the sum of all the (different) position (or occurrences) of an element relative to the occurrence of other elements. (Op. cit., p.15-16).

É possível perceber que há vários pontos de encontro entre o positivismo e o estruturalismo. E isso não é por acaso: como já citei anteriormente, o ideal científico que permeia o pensamento dessas correntes é baseado na objetividade, na imparcialidade e na descrição generalizada. Em outras palavras, buscam (de forma indutiva) leis, a partir de fatos particulares, para a aplicação (de forma dedutiva) a outros fatos. Esse é basicamente o elo de ligação entre as duas escolas.

\section{Conclusão}

Autores que se debruçaram sobre as questões do descritivismo falam da influência política que essa doutrina recebeu; de sua abordagem positivista; do momento pré-chomskyano; da influência behaviorista e do olhar bloomfieldiano no ensino da gramática.

Borba (1991), por exemplo, afirma que a lingüística descritiva, nos EUA recebeu força pelo interesse americano na integração nacional, fato que propiciou uma união do descritivismo com a antropologia, que resultou no aperfeiçoamento de técnicas de abordagem de culturas indígenas. Para ele, é característica da lingüística ser uma ciência que recebe contribuição ou retração de diversos fatores.

Para Leroy (1971), os descritivistas foram ativos no desenvolvimento de uma lingüística estruturalista, sobretudo pelos seus métodos, aplicados às línguas indígenas da América, que, embora ainda faladas, estavam para desaparecer. $\mathrm{O}$ autor lembra ainda o fato de que Bloomfield era um mecanicista. O mecanicismo se apresentou "como um sistema positivista que considera a linguagem, a exemplo de outras atividades humanas, uma conseqüência natural de ações e reações dos diferentes elementos que constituem o corpo humano." (LEROY, 1971, p. 149-150).

Dascal (1978) confirma esse aspecto positivista da teoria descritivista, confirmando o que mencionei anteriormente em relação à garantia que isso dava sobre a cientificidade da disciplina. Essa "garantia”, era dada pelo rigor na definição nos procedimentos e conceitos que envolviam a descrição de uma determinada língua por meio de um corpus:

Nesta preocupação com a definição precisa dos procedimentos de descoberta levada ao extremo por Bloomfield e Harris, podemos discernir a influência de concepções positivistas do método da ciência, como o operacionismo (Bridgman), que considera um conceito teórico legitimamente 'científico' somente se a ele

\footnotetext{
${ }^{7}$ Essa era a questão de algumas frases formadas na língua, mas que seriam desprovidas de sentido (agramaticais). Essas não eram frases consideradas como sendo da língua.
} 
corresponde uma série de 'operações’ bem definidas ao nível observacional. A observação estrita de tais preceitos metodológicos (ou de outros similares, também provenientes do positivismo indutivista) seria a única maneira de garantir, aos olhos dos praticantes do paradigma estruturalista, a cientificidade da lingüística. Daí a importância vital que atribuíam à formulação de procedimentos de descoberta rigorosos e à sua aplicação a fenômenos observáveis, isto é, a um corpus. (DASCAL, 1978, p. 27).

Lemle (s/data, p. 55), num texto intitulado “O novo estruturalismo em lingüística: Chomsky”, diz que o modelo chomskyano é uma "corrente revolucionária na lingüística” em oposição à "lingüística da primeira metade deste século [século $X X$ ] que vem sendo vista como um inter-regno, em que certos valores positivos foram cultivados, tais como a consciência da necessidade de precisão formal e acuidade observacional”. Petter completa:

As análises lingüísticas efetuadas, até os anos 1950, pelos seguidores de Saussure, na Europa, e dos norteamericanos Bloomfield e Harris conformavam-se à teoria descritivista, que julgava a descrição dos fatos suficientes para explicá-los. Chomsky, a partir do final dos anos 50, propõe uma análise lingüística prenda-se menos aos dados e preocupe-se mais com a teoria. (PETTER, 2005, p. 21).

A descrição dos bloomfieldianos era possível para qualquer língua ou dialeto, pois possuíam uma distribuição diferente dos elementos e, conseqüentemente, uma gramática diferente. Ilari afirma que "é difícil não ver sobre uma outra roupagem uma reafirmação da tese saussuriana da arbitrariedade ${ }^{8}$ na posição dos bloomfieldianos de que cada língua teria sua gramática própria e que as categorias gramaticais seriam obtidas dos fatos.” (ILARI, 2004, p. 77-78).

Gleason confirma isso, mas lembra que há alguns traços que estão presentes em todas as línguas.

Só se pode ter um quadro verdadeiro da linguagem, observando as línguas com a maior objetividade. Uma tal perspectiva dará relevo à arbitrariedade, à sua imensa complexidade e ao elevado grau de adequação aos seus propósitos - traços estes que são partilhados por todas as línguas, apesar das suas divergências. (GLEASON(1978: 3-4).

Esses “traços” apontados por Gleason parecem prever o pensamento de Chomsky, que, no final dos anos 50 e, sobretudo, a partir dos anos 60, propõe um olhar para as semelhanças entre as línguas e considera quase superficial a diferença existente entre elas, opondo-se, portanto, à posição descritivista.

Uma questão interessante sobre o descritivismo era por que essa corrente atribuía muita importância aos sons da língua? Langacker tenta responder essa pergunta apontando para uma série de fatores. Aliado a isso, tece uma crítica à tendência descritivista em seguir o behaviorismo:

\begin{abstract}
A tradição anterior da lingüística histórica baseava-se grandemente nos sistemas de som das línguas; a lingüística descritiva herdou essas tendências, juntamente com a de buscar regularidades nos sistemas de sons. Simultaneamente, aumentava o interesse pela descrição de línguas desconhecidas ou pouco conhecidas, especialmente línguas indígenas norte-americanas. Para estudar uma língua desconhecida, uma das primeiras coisas que o lingüista deve fazer é dominar seus sons e estabelecer um sistema para transcrever suas frases. Além disso, a influência poderosa e infeliz do behaviorismo na psicologia deixou sua marca. A doutrina pseudocientífica de que apenas um comportamento manifesto e observável externa entre os lingüistas de se concentrarem nos sistemas de sons, ignorando os domínios mais abstratos do significado e da sintaxe. (LANGACKER, 1977, p.18).
\end{abstract}

O autor comemora a mudança nesse pensamento, dizendo que a lingüística moderna passou a considerar o significado e a sintaxe para a compreensão de uma língua. Reconheceram o fenômeno psicológico na língua sem considerar apenas um comportamento único. Disso resultou a gramática gerativa, corrente seguida por Langacker.

Câmara Jr., nas duas passagens a seguir, dá uma idéia geral sobre qual foi o resultado do do descritivismo:

A língua foi vista numa hierarquia de estruturas superpostas, os níveis estruturais, referentes sucessivamente ${ }^{8}$ Arbitrariedade: a ausência de qualquer conexão necessária entre a forma de uma palavra e seu significado. Para maiores detalhes, cf. Trask (2004: 36-
37). 
à fonologia, à gramática, ou ‘tática’ formal, e à semântica (...). O lingüista procura situar-se sempre num nível determinado e evitar as interferências de níveis na descrição global da língua. (CÂMARA JR., p. 25).

Ao mesmo tempo, levantou-se um problema epistemológico, qual é o de saber se a estrutura resultante desse trabalho de análise corresponde a uma realidade imanente ou é uma construção técnica que se projeta na substância lingüística para melhor explorá-la. (Idem, p. 26).

Para Câmara Jr., o hocus-pocus (arranjo de mágica)é que predomina no estruturalismo bloomfieldiano, dando-lhe um caráter mais estético que propriamente científico. Por esse motivo os descritivistas se afastam de Saussure e Sapir, que buscam de maneira implícita estrutura que sejam reais e objetivas:

No hocus-pocus [arranjo de mágica] impera pois a obsessão de chegar a um sistema. Pode trazer, como admite Householder (...) 'conveniência metodológica e prazer estético’, mas como também ele adverte, não se confunde com 'a necessidade lógica e científica'. (Ibidem).

Como tratei no final do item 2.5, é inegável a crítica dos descritivistas à gramática tradicional. Hill (1972) confirma isso e diz que, as escolas estruturalistas americanas que fizeram uma abordagem empírica, ou seja, a partir dos dados, objetivavam contrapor-se à gramática escolar tradicional, que privilegiava a escrita clássica e literária e, muitas vezes, considerava erro as formas nunca faladas, em oposição às corretas, as únicas dignas de estudo.

Embora muitas doutrinas empiristas e positivistas tenham caído por terra em nossa época, não é difícil perceber ainda que muitas análises (não só lingüísticas) colocam na verificação dos fatos ou na "importação” de teorias de outras disciplinas a comprovação de hipóteses ou a indução de leis de funcionamento de seu objeto de estudo. Se, como diz o Ilari (2004), muitos dos lingüistas modernos têm raízes estruturalistas, é possível dizer que têm também resquícios positivistas.

\section{REFERÊNCIAS}

BENVENISTE, E. Problemas de lingüística geral I. 2.ed. Campinas: Pontes, 1988. Trad. por Maria da Glória Novak e Maria Luiza Néri, do original em francês Problèmes de Linguistique Générale (1966).
BLOOMFIELD, L. Language. Holt, Rinehart and Winston, 1961.[1. edição: 1933].

BORBA, F. S. Introdução aos estudos lingüísticos. Campinas: Pontes, 1991.

CÂMARA Jr., J. M. O estruturalismo lingüístico. Revista Tempo Brasileiro. n. 15/16. Sem data, p. 5-43.

COMTE, A. O espírito positivo. Porto-Portugal: Rés-Editora. Sem data.

. Curso de filosofia positiva. 2. ed. São Paulo: Abril Cultural, 1983. Coleção “Os pensadores” v. 33.

CORNEILLE, J. P. A linguística estrutural: seu alcance e seus limites. Coimbra-Portugal: Livraria Almeidina, 1982. Trad. por Fernanda Dantas Ferreira, do original em francês $L a$ linguistique structurale - sa portée, sés limites (1976).

DASCAL, M (org.). Fundamentos metodológicos da lingüística. v. 1. São Paulo: Global, 1978.

GLEASON, H. A. Introdução à linguística descritiva. LisboaPortugal: Fundação Calouste Gulbenkian, 1978. Trad. por João Pinguelo, do original em inglês An Introduction to Descriptive Linguistics (1955).

KOLAKOWSKI, L. Positivism philosophy. Penguin Books, 1972.

HARRIS, Z. S. Structural linguistics. Chicago - EUA: Phoenix Book (The University of Chicago Press), 1951.

HILL, A. A. Aspectos da lingüística moderna. São Paulo: Cultrix, 1972. Trad. do original em inglês Linguistics. (1966).

ILARI, R. O estruturalismo lingüístico: alguns caminhos. In: MUSSALIN, F. \& BENTES, A. C. (orgs.) Introdução à linguística: fundamentos epistemológicos. v.3. São Paulo: Cortez, 2004, p. 53-92.

LANGACKER, R. W. A linguagem e sua estrutura. 3.ed. Petrópolis: Vozes, 1977. Trad. por Gilda M. de C. Azevedo, do original em inglês Language and its Structure (1967).

LEMLE, M. O novo estruturalismo em lingüística: Chomsky. Revista Tempo Brasileiro. n. 15/16. Sem data, p. 55-69.

LEPSCHY, G.C. A lingüística estrutural. 2. ed. São Paulo: Perspectiva, 1975. Trad. por Nites Therezinha Feres, do original em italiano La Linguistica Struturale (1966).

LEROY, M. As grandes correntes da lingüística moderna. 2. ed. São Paulo: Cultrix, 1971. Trad. por Isidoro Blinkstein e José Paulo Paes, do original em francês Les grands conrants de la linguistique moderne (1967).

LYONS, J. Linguagem e lingüística. Rio de Janeiro: LTC, 1987. Trad. por Marilda W. Averbug e Clarisse S. de Souza, do original em inglês Language and Linguistics (1981).

PETTER, M. Linguagem, língua, lingüística. In: FIORIN, J. L. 
(org.). Introdução à linguistica: objetos teóricos. 4. ed. São Paulo: Contexto, 2005.

PINTO, P. R. M. Aspectos da crítica de Hume ao princípio da causalidade. In: CARVALHO, M. C. M. (org.) A filosofia analítica no Brasil. Campinas: Papirus, 1995, p. 51-68.

REALE, G. \& ANTISERI, D. História da filosofia: a filosofia pagã. v. 1. São Paulo: Paulus, 2003.

RIBEIRO Jr., João. O que é positivismo. São Paulo: Brasiliense, 1996. Coleção Primeiros passos.

TRASK, R.L. Dicionário de linguagem e lingüística. São Paulo: Contexto, 2004. Trad. por Rodolfo Ilari, do original em inglês Key Concepts in Language and Linguistics (2004). 